\title{
Anaphylaxis, CTCAE
}

National Cancer Institute

\section{Source}

National Cancer Institute. Anaphylaxis, CT CAE. NCI Thesaurus. Code C143282.

A disorder characterized by an acute inflammatory reaction resulting from the release of histamine and histamine-like substances from mast cells, causing a hypersensitivity immune response. Clinically, it presents with breathing difficulty, dizziness, hypotension, cyanosis and loss of consciousness and may lead to death. 